\title{
Reply to: Totally laparoscopic versus laparoscopically assisted distal gastrectomy for gastric cancer
}

\author{
Osamu Ikeda $\cdot$ Yoshihisa Sakaguchi • \\ Yasushi Toh $\cdot$ Hideo Baba
}

Published online: 9 December 2009

(C) Springer Science+Business Media, LLC 2009

Letter to the Editor,

We thank Dr. Hottenrott Christof for his informative and insightful comments about our article, which describes the advantages of totally laparoscopic distal gastrectomy (TLDG) compared with laparoscopically assisted distal gastrectomy (LADG). He speculated that TLDG can improve the cosmesis and the quality of laparoscopic procedures, including the reconstruction of the digestive tract by avoiding mini-laparotomy. Thus, TLDG promises further quality of life improvement for the patient. We agree with his opinion. In our study, we fortunately experienced no severe postoperative complications nor complications related to the anastomosis even in the LADG group [1]. However, we often encountered difficulties performing the anastomosis in the narrow and restricted space through a mini-laparotomy, especially under the following conditions: 1) obese patients with thick abdominal walls; 2) patients whose remnant stomach was small (e.g., a case with gastric cancer located in relatively proximal portion of the middle third stomach).

In Japan and Korea, the laparoscopic distal gastrectomy for early gastric cancer has been a common operation. Laparoscopic distal gastrectomies have several advantages,

O. Ikeda $(\bowtie) \cdot$ H. Baba

Department of Gastroenterological Surgery, Graduate School of Medical Sciences, Kumamoto University, Honjo 1-1-1,

Kumamoto 860-8556, Japan

e-mail: ikecho@v101.vaio.ne.jp

Y. Sakaguchi · Y. Toh

Department of Gastroenterological Surgery, National Kyushu Cancer Center, Notame 3-1-1, Fukuoka 811-1395, Japan such as less wound pain, quicker recovery, and shorter hospital stay, compared with open distal gastrectomies [24]. However, these advantages rely on the premise that laparoscopic gastrectomy is performed by oncologically adequate, safe, and secure procedures. In LADG, lymph node dissection is performed laparoscopically under the magnified and excellent view of laparoscopy. However, resection of the stomach and anastomosis are performed with a direct view through a mini-laparotomy, which is much poorer than under laparoscopy [1].

We concluded that totally laparoscopic approaches provide high quality of operation and will be more useful techniques for gastric cancer treatments.

Disclosures Drs. Ikeda, Sakaguchi, Toh, and Baba have no conflicts of interest or financial ties to disclose.

\section{References}

1. Ikeda O, Sakaguchi Y, Aoki Y, Harimoto N, Taomoto J, Masuda T, Ohga T, Adachi E, Toh Y, Okamura T, Baba H (2009) Advantages of totally laparoscopic distal gastrectomy over laparoscopically assisted distal gastrectomy for gastric cancer. Surg Endosc 23:2374-2379

2. Kitano S, Shiraishi N, Fujii K, Yasuda K, Inomata M, Adachi Y (2002) A randomized controlled trial comparing open vs laparoscopy-assisted distal gastrectomy for the treatment of early gastric cancer: an interim report. Surgery 131:S306-S311

3. Nagai Y, Tanimura H, Takifuji K, Kashiwagi H, Yamoto $H$, Nakatani Y (1995) Laparoscope-assisted Billroth I gastrectomy. Surg Laparosc Endosc 5:281-287

4. Uyama I, Sugioka A, Fujita J, Komori Y, Matsui H, Soga R, Wakayama A, Okamoto K, Ohyama A, Hasumi A (1999) Completely laparoscopic extraperigastric lymph node dissection for gastric malignancies located in the middle or lower third of the stomach. Gastric Cancer 2:186-190 